\title{
Prevotella micans sp. nov., isolated from the human oral cavity
}

Correspondence William G. Wade william.wade@kcl.ac.uk
Julia Downes, ${ }^{1}$ Minchuan Liu, ${ }^{1,2}$ Eija Kononen ${ }^{3,4}$ and William G. Wade ${ }^{1}$

'King's College London Dental Institute at Guy's, King's College and St Thomas' Hospitals, Infection Research Group, London SE1 9RT, UK

${ }^{2}$ West China College of Stomatology, Sichuan University, Chengdu, Sichuan 610041, PR China

${ }^{3}$ National Public Health Institute (KTL), Helsinki, FI-00300 Helsinki, Finland

${ }^{4}$ Institute of Dentistry, University of Turku, Fl-20520 Turku, Finland

Four strains of anaerobic Gram-negative bacilli isolated from the human mouth were characterized using a variety of phenotypic and genotypic tests. The strains were found to comprise a homogeneous group and $16 \mathrm{~S}$ rRNA gene sequence analysis revealed them to be distinct from but related to a loose cluster of Prevotella species including Prevotella buccalis, Prevotella nanceiensis and Prevotella marshii. A novel species, Prevotella micans sp. nov., is proposed to accommodate these strains. Prevotella micans is saccharolytic and produces acetic, isovaleric and succinic acids and minor amounts of isobutyric acid as end products of fermentation. The $\mathrm{G}+\mathrm{C}$ content of the DNA of the type strain is $46 \mathrm{~mol} \%$. The type strain of Prevotella micans is E7.56 ${ }^{\top}\left(=\right.$ DSM $21469^{\top}=$ CCUG $\left.56105^{\top}\right)$.
Members of the genus Prevotella are among the most commonly isolated organisms among the human oral microbiota. Although a number of novel species have been proposed in recent years (Downes et al., 2005, 2007; Sakamoto et al., 2004, 2005a, b), molecular identification techniques such as $16 \mathrm{~S}$ rRNA gene sequence analysis continue to reveal additional un-named taxa. The aim of this study was to characterize four strains isolated from the human mouth by means of a range of microscopic, biochemical and molecular techniques.

Strain E7.56 ${ }^{\mathrm{T}}$ was obtained from necrotic pulp, strain 4D22 from subgingival plaque in a deep periodontal pocket and strains $\mathrm{AHN} 8723$ and $\mathrm{AHN} 8376$ from the gingival crevices of two children. Strains were grown at $37{ }^{\circ} \mathrm{C}$ on fastidious anaerobe agar (FAA; LabM) supplemented with $5 \%$ horse blood under anaerobic conditions $\left(80 \% \mathrm{~N}_{2}\right.$, $10 \% \mathrm{H}_{2}, 10 \% \mathrm{CO}_{2}$ ) in an anaerobic workstation (Don Whitley Scientific). Colony morphologies were viewed by means of a dissecting microscope and recorded after incubation for 5 days. Cellular morphology was recorded after Gram-staining of smears prepared from 2 day FAA plate cultures. Hanging-drop preparations of $18 \mathrm{~h}$ cultures of peptone-yeast extract-glucose (PYG) broth were examined by phase-contrast microscopy for cellular motility. Transmission electron microscopy was used to examine the

Abbreviation: PRAS, pre-reduced anaerobically sterilized.

The GenBank/EMBL/DDBJ accession numbers for the 16S rRNA gene sequences of Prevotella micans strains E7.56 ${ }^{\top}$ and 4D22 are AF481228 and EU562293, respectively. cell-wall ultrastructure as described previously (Downes et al., 2002).

Biochemical and physiological tests were performed using standard methods (Holdeman et al., 1977; JousimiesSomer et al., 2002). Fermentation tests were performed using pre-reduced, anaerobically sterilized (PRAS) sugars prepared in an anaerobic workstation (Holdeman et al., 1977). Susceptibility to special-potency antibiotic discs [vancomycin $(5 \mu \mathrm{g})$, kanamycin $(1 \mathrm{mg})$ and colistin $(10 \mu \mathrm{g})]$ was determined on FAA (Jousimies-Somer et al., 2002). The presence and amounts of volatile and nonvolatile fatty acids produced as metabolic end products were determined by gas chromatography of PYG broth cultures (Holdeman et al., 1977). Enzyme profiles were generated with the Rapid ID 32A anaerobe identification kit (bioMérieux) using bacteria harvested from Columbia agar plates (LabM) supplemented with $5 \%$ horse blood, according to the manufacturer's instructions.

The $\mathrm{G}+\mathrm{C}$ content of the DNA of strain $\mathrm{E} 7.56^{\mathrm{T}}$ was determined by HPLC as described previously (Wade et al., 1999). The 16S rRNA genes of the strains were sequenced as described previously (Downes et al., 2005). Sequences were assembled using the BioEdit program (Hall, 2007) and their closest relatives identified by BLAST interrogation of the GenBank database (Altschul et al., 1990). Sequences were aligned by CLUSTAL $\mathrm{w}$ within BioEdit and phylogenetic trees were constructed using MEGA version 4 (Tamura et al., 2007), by the neighbour-joining method from distance matrices prepared using the Jukes-Cantor correction. 
Virtually complete sequences of the $16 \mathrm{~S}$ rRNA gene were obtained for all four strains. Pairwise comparisons over 1451 aligned bases showed that the sequences of the four strains did not differ by more than three bases from each other. The group clustered within the genus Prevotella and were grouped in a loose cluster bounded by Prevotella buccalis and Prevotella shahii (Fig. 1). The generally low bootstrap values for the branches in this cluster indicated that little confidence should be placed in the branch topology. Indeed, the $16 \mathrm{~S}$ rRNA gene sequence identity between strain $\mathrm{E} 7.56^{\mathrm{T}}$ and the other strains in this cluster shown in Fig. 1 was very similar in all cases, ranging from $88 \%$ for P. buccalis, Prevotella enoeca, Prevotella pleuritidis and Prevotella stercorea to $91 \%$ for Prevotella marshii.

The four strains were obligately anaerobic, non-motile, pigmenting Gram-negative bacilli that were $0.7 \mu \mathrm{m}$ wide by $1.5-5.0 \mu \mathrm{m}$ long, arranged singularly and as end-to-end pairs. Transmission electron microscope examination of an ultrathin section of strain E7.56 ${ }^{\mathrm{T}}$ showed a typical Gramnegative cell wall, including a thin peptidoglycan layer and an outer membrane (Fig. 2). When viewed under a plate microscope after 5 days of incubation on FAA plates, colonies were $1.2-1.8 \mathrm{~mm}$ in diameter, circular, entire, convex and iridescent with a mottled internal appearance with bright pink to reddish brown colours in the centre and a cream-coloured periphery (Fig. 3). Colony colour could be variable, with some dull brown-coloured colonies also present, especially in older cultures. Overall, pigmentation varied from brown on FAA with $5 \%$ horse blood to dark brown/black on FAA with $5 \%$ rabbit blood. Strains were resistant to the special-potency vancomycin and kanamycin discs and sensitive to colistin. Growth of all strains in peptone-yeast extract (PY) broth produced a moderately turbid suspension ( 2 to $3+$ on a scale of 0 to

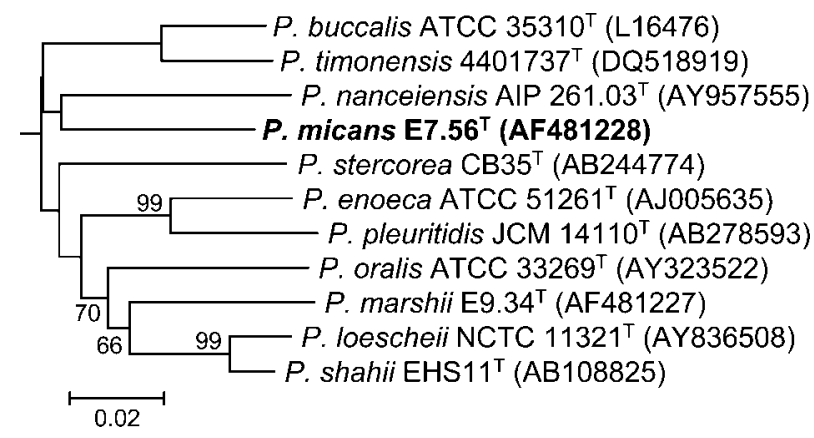

Fig. 1. Phylogenetic tree based on $16 \mathrm{~S}$ rRNA gene sequence comparisons over 1361 aligned bases showing relationships between strain $E 7.56^{\top}$ and related species. The tree was constructed using the neighbour-joining method from a distance matrix constructed from aligned sequences using the JukesCantor correction. Numbers represent bootstrap values for each branch based on data for 100 trees. Accession numbers for $16 \mathrm{~S}$ rRNA sequences are given for each strain. Bar, 0.02 nucleotide substitutions per site.

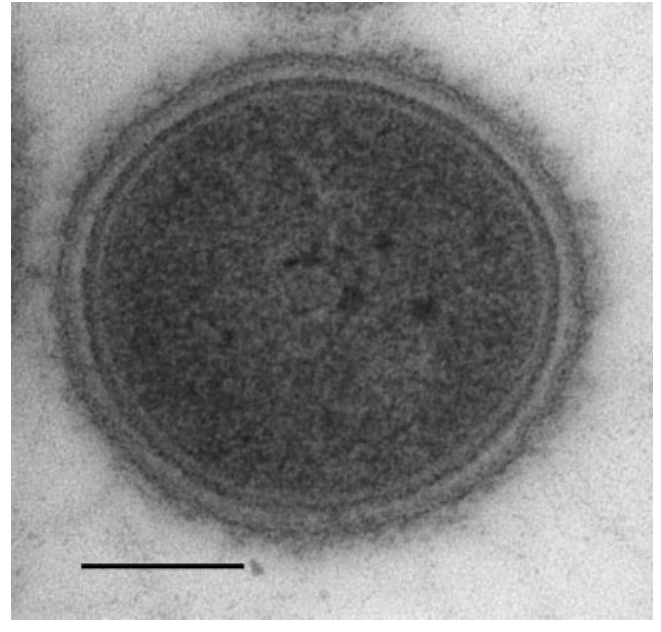

Fig. 2. Transmission electron micrograph of an ultrathin transverse section of a cell of strain $E 7.56^{\top}$. Bar, $100 \mathrm{~nm}$.

$4+$ ). Growth was enhanced (to $4+$ ) by the addition of $1 \%$ fermentable carbohydrates. Strains were saccharolytic (see species description), and moderate to major amounts of acetic, isovaleric and succinic acids and minor to trace amounts of isobutyric acid were produced as end products of metabolism. Indole was produced and gelatin was hydrolysed but other biochemical tests were negative (see species description). The $\mathrm{G}+\mathrm{C}$ content of the DNA of strain $\mathrm{E} 7.56^{\mathrm{T}}$ was $46 \mathrm{~mol} \%$.

The addition of $1 \%$ ferric ammonium citrate solution to actively growing cultures in PRAS PY aesculin broth resulted in black colour development. However, exposure of the broth to UV light revealed bright fluorescence comparable with uninoculated aesculin broth, indicating the presence of aesculin and, therefore, a negative test result for aesculin hydrolysis (Jousimies-Somer et al., 2002).

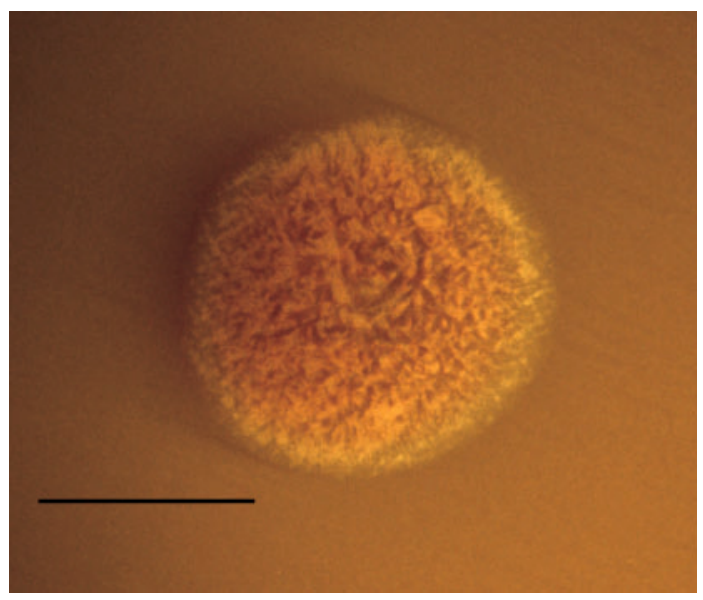

Fig. 3. Colony morphology of strain $E 7.56^{\top}$ grown on FAA plus $5 \%$ horse blood agar after 5 days incubation. Bar, $1 \mathrm{~mm}$. 
All four strains were positive for $\alpha$-galactosidase, $\beta$ galactosidase, $\alpha$-glucosidase, $N$-acetyl- $\beta$-glucosaminidase, $\alpha$-fucosidase, alkaline phosphatase, leucyl glycine arylamidase, alanine arylamidase and indole production in the Rapid ID32A identification panel, while reactions to $\beta$ glucosidase and glutamyl glutamic acid arylamidase were weak and variable. All strains were negative for the remaining 18 enzymes, resulting in a profile of $45^{\circ} /{ }_{1} 1$ $64022 \%$, although weak 6 -phospho- $\beta$-galactosidase reactions were sometimes noted but scored negative.

From the data presented above, it is clear that the four strains studied constitute a homogeneous group that is sufficiently distant in its 16S rRNA gene sequence from Prevotella species with validly published names to warrant creation of a novel species, for which we propose the name Prevotella micans sp. nov.

Biochemical tests that differentiate P. micans from other species in the cluster are shown in Table 1 . However, some pairs of species differ only by a single test, and $16 \mathrm{~S}$ rRNA gene sequence analysis is recommended for the identification of members of this group. P. micans is human oral taxon 378 in the Human Oral Microbiome Database (http://www.homd.org).

\section{Description of Prevotella micans sp. nov.}

Prevotella micans (mi'cans. L. part. adj. micans sparkling, referring to the sparkling, iridescent appearance of the colonies of the organism growing on agar media).

Table 1. Phenotypic characteristics that differentiate Prevotella micans sp. nov. from related Prevotella species

Species: 1, P. oralis; 2, P. micans; 3, P. buccalis; 4, P. loescheii; 5, P. nanceiensis; 6, P. shahii; 7, P. stercorea; 8 , P. enoeca; 9, P. pleuritidis; 10 , P. timonensis; 11, P. marshii. Data for reference species from the original species descriptions. +, Positive; -, negative; v, variable. All taxa are negative for the utilization of arabinose.

\begin{tabular}{|lllllllllllll|}
\hline Characteristic & $\mathbf{1}$ & $\mathbf{2}$ & $\mathbf{3}$ & $\mathbf{4}$ & $\mathbf{5}$ & $\mathbf{6}$ & $\mathbf{7}$ & $\mathbf{8}$ & $\mathbf{9}$ & $\mathbf{1 0}$ & $\mathbf{1 1}$ \\
\hline $\begin{array}{l}\text { Pigmentation } \\
\text { Utilization of: }\end{array}$ & - & + & - & + & - & + & - & - & - & - & - \\
Cellobiose & + & + & + & + & $\mathrm{v}$ & - & - & - & - & - & - \\
Lactose & + & + & + & + & + & + & + & + & + & + & - \\
Mannose & + & + & + & + & + & + & + & $\mathrm{V}$ & + & - & $\mathrm{V}$ \\
Raffinose & + & + & + & + & + & + & + & - & - & - & - \\
Salicin & + & + & - & - & - & - & - & - & - & - & - \\
Sucrose & + & + & + & + & + & + & + & - & - & - & - \\
Indole & - & + & - & - & - & - & - & - & - & - & - \\
production & & & & & & & & & & & \\
Hydrolysis of: & & & & & & & & & & & \\
Aesculin & + & - & + & + & + & - & - & $\mathrm{V}$ & - & - & - \\
Gelatin & $\mathrm{V}$ & + & - & + & - & + & - & + & + & + & + \\
\hline
\end{tabular}

*Pigmentation on blood agar may take up to 14 days and varies from tan to brown/black depending on the species.
The description is based on four strains isolated from the human mouth. Cells are obligately anaerobic, non-motile, pigmented Gram-negative bacilli $(0.7 \mu \mathrm{m} \times 1.5-5.0 \mu \mathrm{m})$. When viewed under a plate microscope after 5 days of incubation on FAA plates, colonies are $1.2-1.8 \mathrm{~mm}$ in diameter, circular, entire, convex and iridescent with a mottled internal appearance with bright pink to reddish brown colours in the centre and a cream-coloured periphery. Growth in broth media produces a moderate turbidity that is enhanced by the addition of fermentable carbohydrates. Cells are saccharolytic and ferment cellobiose, fructose, glucose, lactose, maltose, mannose, melibiose, raffinose, salicin and sucrose, but not arabinose, mannitol, melezitose, rhamnose, ribose, sorbitol, trehalose or xylose. Acetic, isovaleric and succinic acids and minor to trace amounts of isobutyric acid are produced as end products of metabolism. Gelatin is hydrolysed, but not arginine, aesculin or urea. Indole is produced, but not catalase. Nitrate is not reduced. No growth in $20 \%$ bile. The Rapid ID32A profile is $45^{\circ} /{ }_{1} 164022 \%$ and is positive for $\alpha$-galactosidase, $\beta$-galactosidase, $\alpha$-glucosidase, $N$ acetyl- $\beta$-glucosaminidase, $\alpha$-fucosidase, alkaline phosphatase, leucyl glycine arylamidase and alanine arylamidase and weakly and variably positive for $\beta$-glucosidase and glutamyl glutamic acid arylamidase. The $\mathrm{G}+\mathrm{C}$ content of the DNA of the type strain is $46 \mathrm{~mol} \%$.

The type strain is E7.56 ${ }^{\mathrm{T}}\left(=\right.$ DSM $21469^{\mathrm{T}}=$ CCUG $\left.56105^{\mathrm{T}}\right)$, isolated from the human oral cavity.

\section{Acknowledgements}

This work was supported by a grant from the Guy's and St Thomas's Charity (ref. R050724).

\section{References}

Altschul, S. F., Gish, W., Miller, W., Myers, E. W. \& Lipman, D. J. (1990). Basic local alignment search tool. J Mol Biol 215, 403410.

Downes, J., Munson, M. A., Radford, D. R., Spratt, D. A. \& Wade, W. G. (2002). Shuttleworthia satelles gen. nov., sp. nov., isolated from the human oral cavity. Int J Syst Evol Microbiol 52, 1469-1475.

Downes, J., Sutcliffe, I., Tanner, A. C. \& Wade, W. G. (2005). Prevotella marshii sp. nov. and Prevotella baroniae sp. nov., isolated from the human oral cavity. Int J Syst Evol Microbiol 55, 1551-1555.

Downes, J., Sutcliffe, I. C., Booth, V. \& Wade, W. G. (2007). Prevotella maculosa sp. nov., isolated from the human oral cavity. Int J Syst Evol Microbiol 57, 2936-2939.

Hall, T. (2007). BioEdit. Biological sequence alignment editor for Win95/ 98/NT/2K/XP. Carlsbad, CA: Ibis Biosciences. http://www.mbio. ncsu.edu/BioEdit/bioedit.html

Holdeman, L. V. H., Cato, E. P. \& Moore, W. E. C. (1977). Anaerobe Laboratory Manual, 4th edn. Blacksburg, VA: Virginia Polytechnic Institute and State University.

Jousimies-Somer, H., Summanen, P., Citron, D. M., Baron, E. J., Wexler, H. M. \& Finegold, S. M. (2002). Wadsworth Anaerobic Bacteriology Manual, 6th edn. Belmont, CA: Star Publishing. 
Sakamoto, M., Suzuki, M., Huang, Y., Umeda, M., Ishikawa, I. \& Benno, Y. (2004). Prevotella shahii sp. nov. and Prevotella salivae sp. nov., isolated from the human oral cavity. Int J Syst Evol Microbiol 54, 877-883.

Sakamoto, M., Huang, Y., Umeda, M., Ishikawa, I. \& Benno, Y. (2005a). Prevotella multiformis sp. nov., isolated from human subgingival plaque. Int J Syst Evol Microbiol 55, 815-819.

Sakamoto, M., Umeda, M., Ishikawa, I. \& Benno, Y. (2005b). Prevotella multisaccharivorax sp. nov., isolated from human subgingival plaque. Int J Syst Evol Microbiol 55, 1839-1843.
Tamura, K., Dudley, J., Nei, M. \& Kumar, S. (2007). MEGA4: molecular evolutionary genetics analysis (MEGA) software version 4.0. Mol Biol Evol 24, 1596-1599.

Wade, W. G., Downes, J., Dymock, D., Hiom, S. J., Weightman, A. J., Dewhirst, F. E., Paster, B. J., Tzellas, N. \& Coleman, B. (1999). The family Coriobacteriaceae: reclassification of Eubacterium exiguum (Poco et al. 1996) and Peptostreptococcus heliotrinreducens (Lanigan 1976) as Slackia exigua gen. nov., comb. nov. and Slackia heliotrinireducens gen. nov., comb. nov., and Eubacterium lentum (Prevot 1938) as Eggerthella lenta gen. nov., comb. nov. Int J Syst Bacteriol 49, 595-600. 